\title{
Mr. Roentgen's Rays: The Birth of Radiography for Nondestructive Evaluation
}

$X$-ray radiography is extensively used in industry to perform nondestructive evaluations of materials, to examine products and equipment for internal defects, to check assemblies, or to assure the consistency of a solid material.

Back in 1895, when Wilhelm Conrad Roentgen discovered $x$-rays, some of his first experiments were to determine the material properties of certain objects, including a shotgun and a box of weights. Roentgen had accidentally discovered $x$-rays through the phenomenon of fluorescence: while working with an enclosed discharge tube, he noticed that a nearby screen coated with barium platinocyanide began to glow brightly. He soon discovered that metal objects cast shadows when he placed them between the discharge tube and the glowing screen.

A year later, in 1896, Thomas Edison developed the fluoroscope, which allowed the viewing of $x$-ray images. On a sensitive plate, a fluorescent coating - such as zinc cadmium sulfideemitted light when it was struck by $x$-rays, leaving a "shadowgraph" of solid objects placed between the $x$-ray source and the fluoroscope screen. Amidst the sensationalism of the discovery, and doctors using the technique to look at broken bones, $x$-rays were first used to inspect a weld shortly after Roentgen's announcement. The fluoroscope images were dim and coarse, however, and good only for spotting gross defects in material.

$X$-rays were not a useful tool for evaluating materials until an efficient $x$-ray tube became available. Many scientists worked at developing $x$-ray tubes, but 17 years passed before an American physicist, William D. Coolidge, made a major improvement by adding a filament to the tube. Today's x-ray tubes are basically the same as those developed by Coolidge in 1913.

With Coolidge's improved x-ray tube, other engineers began to see the possibilities for using $x$-rays in nondestructive evaluation. In 1919, the Transactions of the Faraday Society discussed several ways to apply Roentgen's rays in engineering.

The American Navy agreed in 1930 to accept radiographic examination for the approval of fusion welds used in boiler drums. Authorities such as the American Petroleum Institute, Lloyd's Register of Shipping, the American Society of Mechanical Engineers, the British Admiralty, and others soonapproved industrial radiography for the inspection of fusion welds in Class I pressure vessels. At about the same time, radiography also became widely used to inspect metal castings, particularly those in aircraft.

During World War II, with the sudden enormous demand for aircraft, casting radiography came of age with its constant use in the examination of aircraft construction. Weld radiography continued to be widely used as well, especially after the British Admiralty assigned teams of radiographers to inspect the welds on new ships under construction. In 1944, the British Director of Naval Construction, Sir Stanley V. Goodall, announced in the journal
Welding that radiography had significantly raised the standards of welding in the shipyard.

The need for flawless welds became even more crucial with the beginning of the atomic age, when the integrity of welds for nuclear pressure vessels and research chambers had to be assured. $X$-ray radiography also has been used in more sophisticated applications to determine the porosity of castings or to detect inclusions, cracks, or differentiation of materials.

In the 1950 s gamma-ray radiography became an alternative to $x$-ray radiography. Nuclear research had produced many gamma-emitting isotopes, giving rise to a new technique that used a small enclosed radioactive source instead of a cumbersome $x$-ray tube to generate the penetrating radiation. Gamma-rays had previously been applied to industrial radiography as early as 1925 , using the natural element radium. Nine years later, engineers began using gaseous radon, which could be concentrated into a small cube only half a millimeter on a side. This allowed for essentially a point source of the gamma-rays, which increased the resolution of the radiograph.

Gamma-ray radiography is more useful when the evaluating device must be portable, or for industries that need to inspect a relatively small number of parts. The initial capital expenditure is less for gamma-ray radiography, but the gamma sources produce radiation significantly weaker than can be produced by an $x$-ray tube, and therefore gammaray work requires much longer exposure times (hours instead of minutes).

Sensitive $x$-ray and gamma-ray film allowed for high-resolution radiographs and also a permanent hardcopy record that fluoroscopes could not produce. But x-ray image intensification procedures allowed fluoroscopy to return to the scene in the late $1950 \mathrm{~s}$, although the applications were mainly directed to medicine. By 1962 over 1,000 x-ray fluoroscopy instruments had been installed in Great Britain alone.

$X$-ray radiography is widely used in industry today to inspect the composition and the thickness of many types of materials. This technique can determine the presence or density of concentrations inside containers or below ground, and can detect changes in density from voids, inclusions, or material variations. $X$-ray radiography can even be used to inspect the internal placement of parts in a large assembly.

KEVIN J. ANDERSON 